\title{
Mortality in former Olympic athletes: retrospective cohort analysis
}

\author{
(ब) (1) OPEN ACCESS
}

\author{
R Zwiers PhD candidate $^{1}$, F W A Zantvoord medical student ${ }^{1}$, F M Engelaer PhD candidate $^{12}$, D \\ van Bodegom assistant professor of medicine ${ }^{12}, \mathrm{~F} \mathrm{~J} \mathrm{G}$ van der Ouderaa chief scientific officer ${ }^{1}, \mathrm{R}$ \\ $\mathrm{G} \mathrm{J}$ Westendorp professor of old age medicine ${ }^{12}$
}

'Leyden Academy on Vitality and Ageing, Rijnsburgerweg 10, 2333 AA Leiden, Netherlands; ${ }^{2}$ Leiden University Medical Centre, Leiden

\begin{abstract}
Objective To assess the mortality risk in subsequent years (adjusted for year of birth, nationality, and sex) of former Olympic athletes from disciplines with different levels of exercise intensity.

Design Retrospective cohort study.

Setting Former Olympic athletes.

Participants 9889 athletes (with a known age at death) who participated in the Olympic Games between 1896 and 1936, representing 43 types of disciplines with different levels of cardiovascular, static, and dynamic intensity exercise; high or low risk of bodily collision; and different levels of physical contact.
\end{abstract}

Main outcome measure All cause mortality.

Results Hazard ratios for mortality among athletes from disciplines with moderate cardiovascular intensity $(1.01,95 \%$ confidence interval 0.96 to 1.07$)$ or high cardiovascular intensity $(0.98,0.92$ to 1.04$)$ were similar to those in athletes from disciplines with low cardiovascular intensity. The underlying static and dynamic components in exercise intensity showed similar non-significant results. Increased mortality was seen among athletes from disciplines with a high risk of bodily collision (hazard ratio $1.11,1.06$ to 1.15$)$ and with high levels of physical contact (1.16, 1.11 to 1.22 ). In a multivariate analysis, the effect of high cardiovascular intensity remained similar (hazard ratio $1.05,0.89$ to 1.25 ); the increased mortality associated with high physical contact persisted (hazard ratio $1.13,1.06$ to 1.21 ), but that for bodily collision became non-significant $(1.03,0.98$ to 1.09$)$ as a consequence of its close relation with physical contact.

Conclusions Among former Olympic athletes, engagement in disciplines with high intensity exercise did not bring a survival benefit compared with disciplines with low intensity exercise. Those who engaged in disciplines with high levels of physical contact had higher mortality than other Olympians later in life.

\section{Introduction}

Public health associations recommend physical exercise because it is associated with lower mortality risks, better mood and cognition, and lower prevalence of cardiovascular disease. ${ }^{1-7}$ However, when Pheidippides ran from Marathon to Athens in 490 BC to announce the Greek victory over the Persians, he died on arrival. As his case illustrates, exercise of high intensity can also place great strain on the body and can cause serious injuries and damage. ${ }^{8}$ The question is whether regular high intensity exercise is associated with a lower or higher mortality risk. When the first modern Olympic Games were held in Athens in 1896, including a marathon run to Athens, the organisers decided to shorten the distance, with the death of Pheidippides in mind. The current distance of $42.195 \mathrm{~km}$ was determined only later during the third Olympics in London, when the royal family requested the race to be from the start at Windsor Castle to the royal stage in the White City Stadium. This year, the Olympic Games were back in London, but whether high intensity exercise is beneficial for reducing mortality risk is still debated. ${ }^{9} 10$

The effect of high intensity exercise on mortality later in life has mostly been studied among professional athletes, using the general population as a control group. The outcomes from these studies differ; some did not find a survival benefit, whereas others showed lower mortality in athletes than in their non-athletic counterparts from the general population. ${ }^{11-24}$ The lower mortality risk of professional athletes compared with the general population could be due to specific social and psychometric characteristics, and whether high intensity exercise 
brings a survival benefit or an increased mortality risk for athletes remains to be elucidated. We analysed mortality patterns in a large historic cohort of athletes who had all participated in the Olympic Games between 1896 and 1936 but performed at different levels of cardiovascular, static, and dynamic intensity exercise.

\section{Methods \\ Study population}

In May 2011 we retrieved a cohort of 21127 former Olympic athletes from the continuously updated Sports Reference database, the largest online database of Olympic athletes. ${ }^{25}$ Figure $1 \Downarrow$ summarises the inclusion process. We included 9889 former Olympic athletes, born between 1830 and 1910, with a known age at death, who participated in at least one of the Summer Olympic Games between 1896 and 1936. We excluded 2162 athletes from nine disciplines that were not mentioned in the classification of the American College of Cardiology. ${ }^{26} \mathrm{We}$ classified skeleton as bobsledding and polo as equestrian, because of the very similar types of exercise. For 7534 athletes, the age at death was unknown owing to an unknown date of birth, date of death, or both. Finally, we excluded 1542 participants born after 1910, as they could possibly be still alive.

\section{Classification of Olympic disciplines}

We classified the 43 Olympic disciplines according to the classification system of the 8th Task Force on the Classification of Sports by the American College of Cardiology. ${ }^{26}$ The classification of cardiovascular intensity sums a static component reflecting maximal voluntary muscle contraction and a dynamic component reflecting maximal oxygen uptake; both were categorised at three levels of intensity-low, moderate, and high. The system also defines three levels of static and dynamic intensity - low, moderate, and high. When an athlete had participated in multiple disciplines, we categorised him/her in the discipline with the highest cardiovascular score. The risk of bodily collision was also classified by the American College of Cardiology. ${ }^{26}$ Finally, we classified the various disciplines as low (non-contact), moderate (limited contact), and high (full contact), according to the classification of contact sports of the American Academy of Pediatrics. ${ }^{27}$ The levels of exercise intensity were similar in athletes who were included in and excluded from this analysis (data not shown).

\section{Statistical analysis}

We calculated hazard ratios for all cause mortality by using a left truncated Cox proportional hazards model, entering participants at the age of first participation in the Olympic Games. All analyses were adjusted for sex, year of birth, and nationality. We used Stata 11 for all calculations.

\section{Results}

We included 9889 athletes from 43 different Olympic disciplines that were classified in various categories of intensity of exercise, risk of bodily collision, and the level of physical contact. The supplementary table summarises the characteristics of these 43 disciplines. Figure $2 \Downarrow$ shows all 43 disciplines stratified for the level of static, dynamic, and cardiovascular intensity, classified according the American College of Cardiology. ${ }^{26}$

We firstly calculated hazard ratios for mortality dependent on different levels of exercise intensity. As the participants came from different birth cohorts, we adjusted all our analyses for year of birth, which, as expected, was correlated with mortality.
Next, we adjusted for sex and nationality, which were also correlated with mortality (data not shown). Table $1 \Downarrow$ shows hazard ratios for mortality for different levels of cardiovascular, static, and dynamic intensity in both univariate and multivariate analyses. Engagement in disciplines with increasing cardiovascular intensity was not associated with a significantly higher mortality risk; the hazard ratio for moderate intensity was 1.01 (95\% confidence interval 0.96 to $1.07 ; \mathrm{P}=0.71)$, and that for high intensity was $0.98(0.92$ to $1.40 ; \mathrm{P}=0.46)$.

Multivariate analysis showed similar results (table $1 \Downarrow$ ). Analysis of the static and dynamic components separately showed similar non-significant results. Univariate analysis showed a small beneficial effect of moderate static exercise, but this was not reflected in a lower hazard ratio in athletes engaged in disciplines with high intensity static exercise.

We also studied the effect of bodily collision and physical contact on mortality (table $2 \Downarrow$ ). Athletes engaged in disciplines with a high risk of bodily collision had an $11 \%$ higher mortality risk compared with those who were not exposed (hazard ratio $1.11,1.06$ to $1.15 ; \mathrm{P}<0.001)$. When comparing athletes who had performed in disciplines with various levels of physical contact, we found that those who participated in sports with only moderate contact did not have a higher mortality risk. However, athletes who were exposed to high levels of physical contact had a $16 \%$ higher mortality risk compared with those with low physical contact (hazard ratio $1.16,1.11$ to $1.22 ; \mathrm{P}<0.001$ ). These higher mortality risks remained similar in the multivariate analysis, whereas the hazard ratio for bodily collision became non-significant.

We additionally did similar analyses in various subgroups-men only, deaths after age 50, born before 1900, and born after 1900 (fig $3 \Downarrow$ ). In none of the subgroups was exercise at high cardiovascular intensity associated with a reduction in mortality risk. However, we found a significant higher mortality risk in all these subgroups for risk of bodily collision and high physical contact.

\section{Discussion}

Our results show that former Olympic athletes who engaged in disciplines with high cardiovascular intensity had similar mortality risks to athletes from disciplines with low cardiovascular intensity. This would indicate that engaging in cycling and rowing (high cardiovascular intensity) had no added survival benefit compared with playing golf or cricket (low cardiovascular intensity).

Although comparing modern sporting activity with that during the first series of the games is a daunting task, this analysis is sobering for all those athletes who trained so hard to qualify for the London Olympics in 2012. Moreover, our analyses point to a potential risk for those engaged in disciplines with a high risk of bodily collision or high levels of physical contact. As the higher mortality risk persisted for death after age 50, this increased risk could not be explained by the death of young athletes due to trauma. We consider it more likely that the higher mortality risk reflects the effect of a gradual accumulation of multiple bodily injuries during sporting activities. Previous studies have shown that bodily collisions or fierce physical contacts are responsible for a large proportion of the total burden of injuries. ${ }^{82}$ These injuries may have longlasting detrimental effects, in line with the generalised theory of ageing. For instance, repetitive blows to the head, especially in boxers, are associated with cognitive impairment, early onset dementia, and reduced life expectancy. ${ }^{29} 30$ 
Our findings stand in contrast to several other studies showing a benefit to late life mortality risk in very well trained athletes. ${ }^{31-34}$ A possible explanation could be that these studies included only exercise of moderate intensity. Other studies, however, described a late life survival advantage for endurance athletes who had trained at high physical intensity. ${ }^{22-24}{ }^{35}$ All previous observations may be subject to bias, however, as trained athletes differ from the general population in more ways than just physical fitness. We consider our comparison of former Olympic athletes who performed their sports at different physical intensity to be more robust than a comparison between trained athletes and people from the population at large. This interpretation is strengthened by the fact that outcomes were congruent in all domains of physical intensity (for example, cardiovascular, static and dynamic intensity).

In this study, we used data from athletes who participated in the Olympic Games between 1896 and 1936, so outcomes reflect late life consequences of intensive exercise programmes that were in vogue 70 to 110 years ago. Since then, training programmes, especially on a (semi)professional level, have changed substantially. Top athletes now not only train more often and more intensely, but training has also become more individualised and specifically focused. Moreover, medical care to prevent permanent damage is undoubtedly better and could explain why in the past the potential benefits of intensive physical training were overwhelmed by trade-offs later in life. We do not have access to any data that allow for a valid comparison of use of anabolic steroids and other stimulating substances, but many people would argue that their use was probably less prevalent in the past than it is now. For all of these reasons, care is needed in extrapolating our findings to the late life effects of current training schemes.

Regarding the negative effect of bodily collision and fierce physical contact, current sporting activities are much more extreme with regard to velocity, $g$ force, and other mechanical strains. Collisions and physical injuries could therefore have more effect nowadays, despite better protective aids and medical treatment. Our findings could well underestimate the late life effects of the gradual accumulation of permanent damage due to repeated collisions and injuries to which top athletes are exposed. This being said, several potential confounders could decrease or further increase the hazard ratios for mortality that we have found. These include unknown factors such as the total number of years spent in training, age at which intensive training ceased, intensity of exercise after athletes withdrew from competitive sports, specific behaviour in specific types of sport, and specific personal characteristics depending on the type of sport. The beneficial effects of exercise could also be counterbalanced by detrimental effects of (acute) cessation of physical exercise resulting in a net neutral effect.

Although we did not find evidence that former Olympic athletes from disciplines involving high intensity exercise have a higher mortality risk than other former Olympians, people should think for a moment before engaging in disciplines with risk of bodily collision or fierce physical contact. This notion may help to explain a historical fact. Before Pheidippides exclaimed

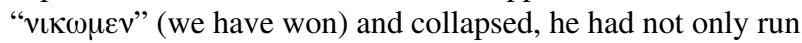
from Marathon to Athens but had fought in the battle of Marathon before that. It is tempting to speculate that it was not the run from Marathon to Athens but the effect of armed force that led to his tragic death.

Contributors: RZ and FWAZ contributed equally to this work; they collected and analysed the data with assistance from FE and DvB. All authors contributed to writing the article and participated in the scientific debate. FE is the guarantor.

\section{Funding: None.}

Competing interests: All authors have completed the ICMJE uniform disclosure form at www.icmje.org/coi_disclosure.pdf (available on request from the corresponding author) and declare: no support from any organisation for the submitted work; no financial relationships with any organisations that might have an interest in the submitted work in the previous three years; no other relationships or activities that could appear to have influenced the submitted work.

Ethical approval: Not needed. All calculations used publicly available data.

Data sharing: No additional data available.

1 Erlichman J, Kerbey AL, James WP. Physical activity and its impact on health outcomes. Paper 1: The impact of physical activity on cardiovascular disease and all-cause mortality: an historical perspective. Obes Rev 2002:3:257-71.

2 Bauman AE. Updating the evidence that physical activity is good for health: an epidemiological review 2000-2003. J Sci Med Sport 2004;7(1 suppl):6-19.

3 Melzer K, Kayser B, Pichard C. Physical activity: the health benefits outweigh the risks. Curr Opin Clin Nutr Metab Care 2004;7:641-7.

4 Lippi G, Schena F, Salvagno GL, Montagnana M, Ballestrieri F, Guidi GC. Comparison of the lipid profile and lipoprotein (a) between sedentary and highly trained subjects. Clin Chem Lab Med 2006;44:322-6.

5 Williams MA, Haskell WL, Ades PA, Amsterdam EA, Bittner V, Franklin BA, et al. Resistance exercise in individuals with and without cardiovascular disease: 2007 update: a scientific statement from the American Hearth Association Council on Clinical Cardiology and Council on Nutrition, Physical Activity, and Metabolism. Circulation 2007:116:572-84.

6 Haskell WL, Lee IM, Pate RR, Powell KE, Blair SN, Franklin BA, et al. Physical activity and public health: updated recommendation for adults from the American College of Sports Medicine and the American Heart Association. Circulation 2007;116:1081-93.

7 Physical Activity Guidelines Advisory Committee. Physical Activity Guidelines Advisory Committee report, 2008. US Department of Health and Human Services, 2008.

8 Backx FJ, Beijer HJ, Bol E, Erich WBM. Injuries in high-risk persons and high-risk sports: a longitudinal study of 1818 school children. Am J Sports Med 1991;19:124-30.

9 Blair SN, Kohl HW, Gordon NF, Paffenbarger RS. How much physical activity is good for health? Annu Rev Public Health 1992;13:99-126.

10 Blair SN, Connelly JC. How much physical activity should we do? The case for moderate amounts and intensities of physical activity. Res Q Exerc Sport 1996;67:193-205.

11 Lee IM, Skerrett PJ. Physical activity and all-cause mortality: what is the dose-response relation? Med Sci Sports Exerc 2001;33(6 suppl):S459-71.

12 Beaglehole R, Stewart A. The longevity of international rugby players. $N Z$ Med J 1983;96:513-5.

13 Belli S, Vanacore N. Proportionate mortality of Italian soccer players: is amyotrophic lateral sclerosis an occupational disease? Eur J Epidemiol 2005;20:237-42.

14 Kuss O, Kluttig A, Greiser KH. Longevity of soccer players: an investigation of all German internationals from 1908 to 2006. Scand J Med Sci Sports 2011;21:e260-5.

15 Schnohr P. Longevity and causes of death in male athletic champions. Lancet 1971;2:1364-6.

16 Waterbor J, Cole P, Delzell E, Andjelkovich D. The mortality experience of major-league baseball players. N Engl J Med 1998;318:1278-80.

17 Yamaji K, Shephard RJ. Longevity and causes of death of athletes. J Hum Ergol (Tokyo) 1977;6:15-27.

18 Gajewski AK, Posnanska A. Mortality of top athletes, actors and clergy in Poland: 1924-2000 follow-up study of the long term effect of physical activity. Eur J Epidemiol 2008;23:335-40.

19 Karvonen MJ, Klemola H, Virkajarvi J, Kekkonen A. Longevity of endurance skiers. Med Sci Sports 1974;6;49-50.

20 Menotti A, Amici E, Gambelli GC, Milazzotto F, Bellotti P, Capocaccia R, et al. Life expectancy in Italian track and field athletes. Eur J Epidemiol 1990;6:257-60.

21 Taioli E. All causes of mortality in male professional soccer players. Eur J Public Health 2007;12:600-4.

22 Kujala UM, Tikkanen HO, Sarna S, Pukkala E, Kaprio J, Koskenvuo M. Disease-specific mortality among elite athletes. JAMA 2001;285:44-5.

23 Sarna S, Sahi T, Koskenvuo M, Kapprio J. Increased life expectancy of world class male athletes. Med Sci Sports Exerc 1993;25:237-44.

24 Teramoto M, Bungum TJ. Mortality and longevity of elite athletes. J Sci Med Sport 2010;13:410-6.

25 Sports Reference. Olympics statistics and history. 2011. www.sports-reference.com/ olympics/.

26 Mitchell JH, Haskell W, Snell P, Van Camp SP. Task force 8: classification of sports. J Am Coll Cardiol 2005:45:1364-7.

27 Rice SG. Medical conditions affecting sports participation. Pediatrics 2008:121:841-8.

28 Hootman JM, Dick R, Agel J. Epidemiology of collegiate injuries for 15 sports: summary and recommendations for injury prevention initiatives. $J$ Athl Train 2007;42:311-9.

29 Bianco M, Fabbricatore C, Sanna N, Fabiano C, Palmieri V, Zeppilli P, et al. Elite athletes: is survival shortened in boxers? Int J Sports Med 2007:28:697-702

30 Xie J, Brayne C, Matthews FE. Survival times in people with dementia: analysis from population based cohort study with 14 year follow-up BMJ 2008;336:258-62

31 Kokkinos $\mathrm{P}$, Sheriff $\mathrm{H}$, Kheirbek R. Physical activity and mortality risk. Cardiol Res Pract 2011;2011:924-45

32 Warburon DE, Nicol CW, Bredin SS. Health benefits of physical activity: the evidence. CMAJ 2006;174:801-9.

33 Woodcock J, Franco OH, Orsini N, Roberts I. Non-vigorous physical activity and all-cause mortality: systematic review and meta-analysis of cohort studies. Int $J$ Epidemiol 2011;40:121-38 


\section{What is already known on this topic}

Modern athletes who performing high intensity exercise have a survival benefit when compared with the general population Intensive exercise places great strain on the human body and can cause serious injuries and damage

\section{What this study adds}

Former Olympic athletes who engaged in disciplines with high cardiovascular intensity had similar mortality risks to those from disciplines with low cardiovascular intensity

Engaging in disciplines with risk of bodily collision or physical contact was associated with a higher mortality risk compared with other disciplines

34 Lee IM, Hsieh CC, Paffenbarger RS Jr. Exercise intensity and longevity in men: the Harvard Alumni Health Study. JAMA 1995;273:1179-84.

35 Kujala UM, Kaprio J, Taimela S, Sarna S. Prevalence of diabetes, hypertension and ischemic hearth disease in former elite athletes. Metabolism 1994;43:1255-60.

Accepted: 14 September 2012

\section{Cite this as: BMJ 2012;345:e7456}

This is an open-access article distributed under the terms of the Creative Commons Attribution Non-commercial License, which permits use, distribution, and reproduction in any medium, provided the original work is properly cited, the use is non commercial and is otherwise in compliance with the license. See: http://creativecommons.org/licenses/bync/2.0/ and http://creativecommons.org/licenses/by-nc/2.0/legalcode. 


\section{Tables}

Table 1| Hazard ratios of mortality for athletes in disciplines with different intensities of exercise

\begin{tabular}{|c|c|c|c|c|}
\hline \multirow[b]{2}{*}{ Intensity } & \multicolumn{2}{|c|}{ Univariate analysis $^{*}$} & \multicolumn{2}{|c|}{ Multivariate analysis $\dagger$} \\
\hline & Hazard ratio $(95 \% \mathrm{Cl})$ & $P$ value & Hazard ratio $(95 \% \mathrm{Cl})$ & $P$ value \\
\hline \multicolumn{5}{|c|}{ Cardiovascular: } \\
\hline Low & Reference & & Reference & \\
\hline Moderate & 1.01 (0.96 to 1.07$)$ & 0.71 & $1.04(0.95$ to 1.15$)$ & 0.40 \\
\hline High & $0.98(0.92$ to 1.04$)$ & 0.46 & $1.05(0.89$ to 1.25$)$ & 0.58 \\
\hline \multicolumn{5}{|l|}{ Static: } \\
\hline Low & Reference & & Reference & \\
\hline Moderate & 0.94 (0.89 to 0.99 ) & 0.02 & 0.93 (0.85 to 1.01$)$ & 0.09 \\
\hline High & 0.99 (0.94 to 1.04$)$ & 0.62 & 0.95 (0.85 to 1.07$)$ & 0.40 \\
\hline \multicolumn{5}{|l|}{ Dynamic: } \\
\hline Low & Reference & & Reference & \\
\hline Moderate & 0.94 (0.89 to 0.99 ) & 0.03 & 0.94 (0.87 to 1.01 ) & 0.09 \\
\hline High & $0.97(0.92$ to 1.02$)$ & 0.19 & $0.94(0.83$ to 1.06$)$ & 0.34 \\
\hline
\end{tabular}

*Adjusted for sex, year of birth, and nationality.

†Additionally includes all types of exercise intensity (cardiovascular, static, and dynamic) in model. 
Table 2| Hazard ratios of mortality for athletes in disciplines with different risk of bodily collision and physical contact

\begin{tabular}{|c|c|c|c|c|}
\hline \multirow[b]{2}{*}{ Sport type } & \multicolumn{2}{|c|}{ Univariate analysis ${ }^{*}$} & \multicolumn{2}{|c|}{ Multivariate analysis $\dagger$} \\
\hline & Hazard ratio $(95 \% \mathrm{Cl})$ & $P$ value & Hazard ratio $(95 \% \mathrm{Cl})$ & $P$ value \\
\hline \multicolumn{5}{|c|}{ Bodily collision: } \\
\hline No & Reference & & Reference & \\
\hline Yes & $1.11(1.06$ to 1.15$)$ & $<0.001$ & 1.03 (0.98 to 1.09$)$ & 0.25 \\
\hline \multicolumn{5}{|c|}{ Physical contact: } \\
\hline Low & Reference & & Reference & \\
\hline Moderate & 0.97 (0.93 to 1.02$)$ & 0.25 & $0.96(0.92$ to 1.01$)$ & 0.16 \\
\hline High & $1.16(1.11$ to 1.22$)$ & $<0.001$ & $1.13(1.06$ to 1.21$)$ & $<0.001$ \\
\hline
\end{tabular}

${ }^{*}$ Adjusted for sex, year of birth, and nationality.

†Additionally includes both bodily collision and physical contact in model. 


\section{Figures}

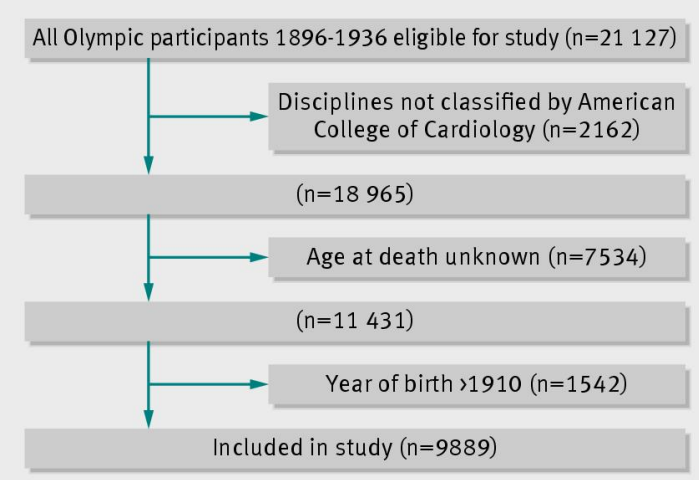

Fig 1 Flow diagram showing inclusion of former Olympic athletes in study

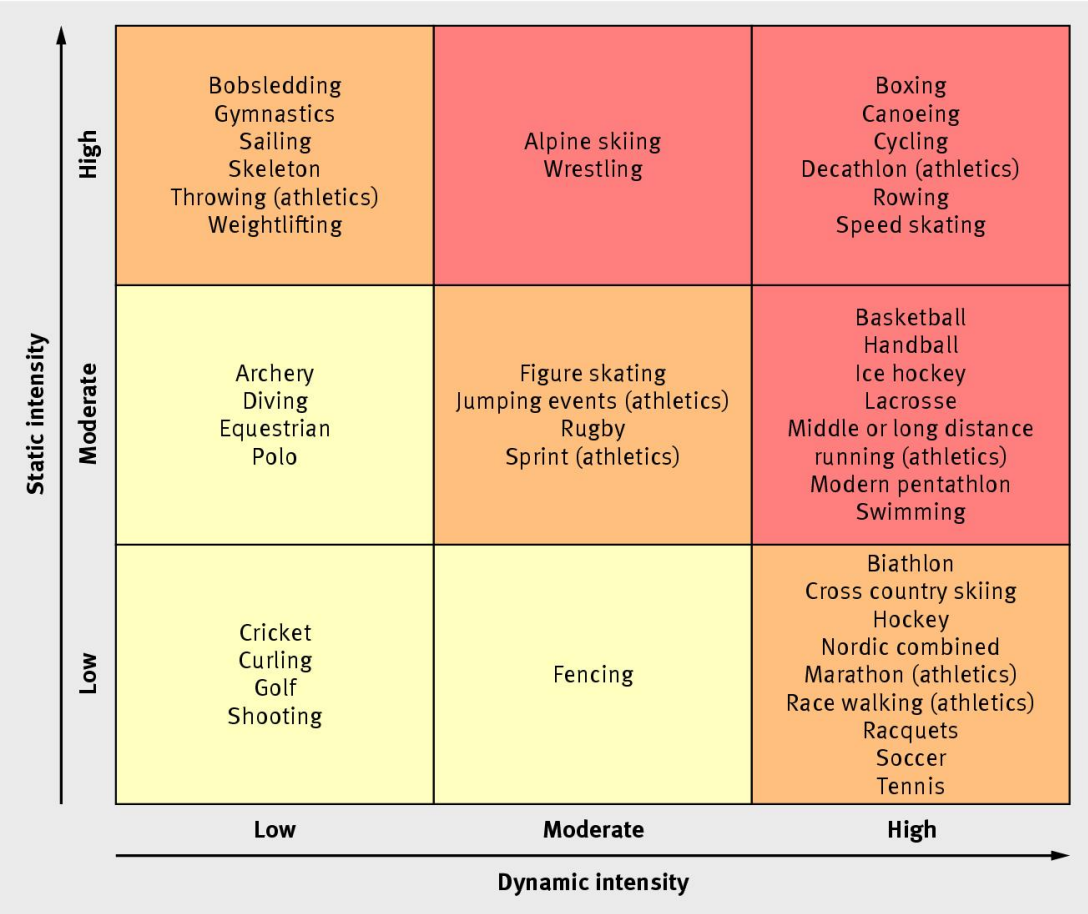

Fig 243 Olympic disciplines classified in categories of static and dynamic intensity, as well as three categories of low, moderate, and high cardiovascular intensity (from yellow to red). ${ }^{26}$ 


\begin{tabular}{|c|c|c|}
\hline & $\begin{array}{c}\text { Hazard ratio } \\
(95 \% \mathrm{CI})\end{array}$ & $\begin{array}{c}\text { Hazard ratio } \\
(95 \% \mathrm{Cl})\end{array}$ \\
\hline \multicolumn{3}{|c|}{ Cardiovascular intensity (high v low) } \\
\hline All athletes & $\rightarrow$ & $0.98(0.92$ to 1.04$)$ \\
\hline Men only & & $0.97(0.91$ to 1.03$)$ \\
\hline Deaths after age 50 only & - & $1.00(0.94$ to 1.06$)$ \\
\hline Born before 1900 only & & $0.97(0.90$ to 1.04$)$ \\
\hline Born after 1900 only & & $0.99(0.87$ to 1.12$)$ \\
\hline \multicolumn{3}{|l|}{ Bodily collision (yes $v$ no) } \\
\hline All athletes & $\rightarrow$ & $1.11(1.06$ to 1.15$)$ \\
\hline Men only & $\leftarrow$ & $1.11(1.07$ to 1.16$)$ \\
\hline Deaths after age 50 only & $\rightarrow$ & $1.13(1.08$ to 1.18$)$ \\
\hline Born before 1900 only & $\rightarrow$ & $1.08(1.03$ to 1.14$)$ \\
\hline Born after 1900 only & $\rightarrow-$ & $1.16(1.08$ to 1.24$)$ \\
\hline \multicolumn{3}{|l|}{ Physical contact (high $v$ low) } \\
\hline All athletes & $\rightarrow$ & $1.16(1.11$ to 1.22$)$ \\
\hline Men only & $\rightarrow$ & $1.18(1.12$ to 1.24$)$ \\
\hline Deaths after age 50 only & $\rightarrow$ & $1.20(1.13$ to 1.26$)$ \\
\hline Born before 1900 only & $\rightarrow$ & $1.16(1.09$ to 1.24$)$ \\
\hline Born after 1900 only & $\rightarrow$ & $1.17(1.08$ to 1.26$)$ \\
\hline & 1.2 & .4 \\
\hline
\end{tabular}

Fig 3 Hazard ratios of mortality (95\% Cls) in former Olympic athletes according to cardiovascular intensity, bodily collision, and physical contact. Analyses were adjusted for sex, year of birth, and nationality 